\title{
Early Detection and Treatment of Psychosis: The Bern Child and Adolescent Psychiatric Perspective
}

\author{
Frauke Schultze-Lutter and Benno G. Schimmelmann \\ University Hospital of Child and Adolescent Psychiatry and Psychotherapy, University of Bern, Bolligenstrasse 111, \\ Haus A, 3000 Bern 60, Switzerland \\ Correspondence should be addressed to Frauke Schultze-Lutter; frauke.schultze-lutter@kjp.unibe.ch
}

Received 26 June 2014; Revised 25 August 2014; Accepted 28 August 2014; Published 9 September 2014

Academic Editor: Jane E. Boydell

Copyright (C) 2014 F. Schultze-Lutter and B. G. Schimmelmann. This is an open access article distributed under the Creative Commons Attribution License, which permits unrestricted use, distribution, and reproduction in any medium, provided the original work is properly cited.

\begin{abstract}
Commonly conceptualized as neurodevelopmental disorders of yet poorly understood aetiology, schizophrenia and other nonorganic psychoses remain one of the most debilitating illnesses with often poor outcome despite all progress in treatment of the manifest disorder. Drawing on the frequent poor outcome of psychosis and its association with the frequently extended periods of untreated first-episode psychosis (FEP) including its prodrome, an early detection and treatment of both the FEP and the preceding at-risk mental state (ARMS) have been increasingly studied. Thereby both approaches are confronted with different problems, for example, treatment engagement in FEP and predictive accuracy in ARMS. They share, however, the problems related to the lack of understanding of developmental, that is, age-related, peculiarities and of the presentation and natural course of their cardinal symptoms in the community. Most research on early detection and intervention in FEP and ARMS is still related to clinical psychiatric samples, and little is known about symptom presentation and burden and help-seeking in the general population related to these experiences. Furthermore, in particular in the early detection of an ARMS, studies often address adolescents and young adults alike without consideration of developmental characteristics, thereby applying risk criteria that have been developed predominately in adults. Combining our earlier experiences described in this paper in child and adolescent, and general psychiatry as well as in both lines of research, that is, on early psychosis and its treatment and on the early detection of psychosis, in particular in its very early states by subjective disturbances in terms of basic symptoms, age-related developmental and epidemiological aspects have therefore been made the focus of our current studies in Bern, thus making our line of research unique.
\end{abstract}

\section{Introduction}

Schizophrenia and other nonorganic psychoses remain one of the most debilitating illnesses $[1,2]$, despite all the progress in treatment that has been made since the introduction of antipsychotics in the 1960s. Though generally conceptualized as a neurodevelopmental disorder, their aetiology is still only poorly understood. Psychotic disorders have a life-time prevalence of approximately $3.5 \%$ [3] and a 12 -month incidence rate of about $0.035 \%$ [4]. They usually first strike early in life, between the ages of 20 and $25[4,5]$; approximately $10-$ $15 \%$ are early-onset psychoses (EOP) manifesting themselves before the age of 18 , and approximately 1-3\% are very-earlyonset psychoses (VEOP) with an onset before the age of 13 [6]. Despite their relatively low prevalence, psychoses are one of the top-ten diseases with regard to disability-adjusted life years (DALYs) [7-9]. Furthermore, the immense indirect costs of these disorders, for example, caused by early and lasting loss of productivity on the part of both patients and their carers, make them one of the most costly disorders for society $[8,9]$.

The high societal and personal cost are driven in part by the poor course that psychoses tend to take after their initial manifestation. A poor course however is, among others, a consequence of the frequently long duration of unrecognized and untreated psychosis (DUP) and illness, including the prodrome (DUI) [10-13] even in persons seeking help early $[14,15]$. An extended prodrome of more than three years precedes the majority of first-episode psychoses (FEP) [13, $16,17]$; however, the gradual progression characteristic of 


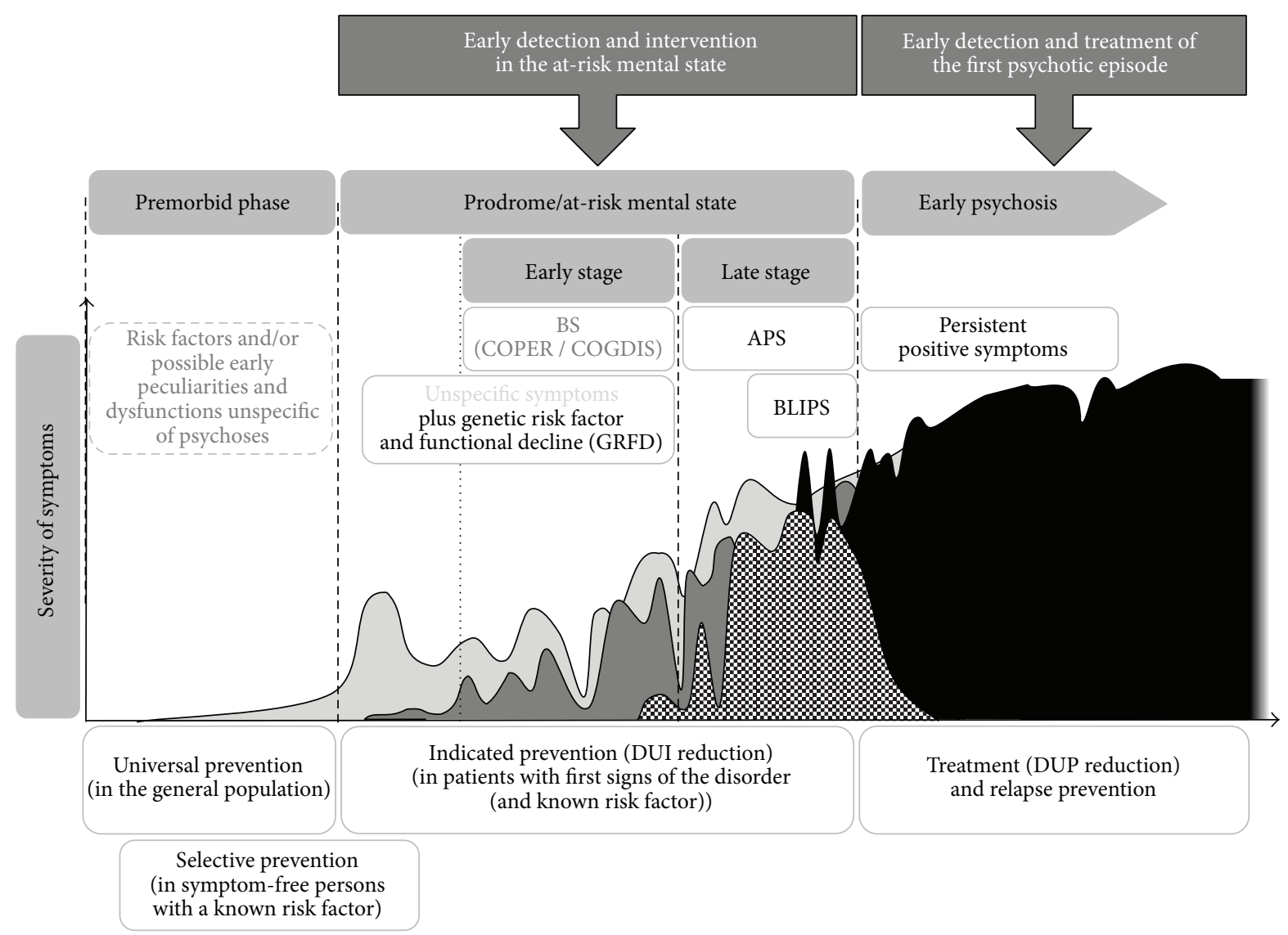

Figure 1: Hypothetical early course of psychosis in relation to primary and secondary preventive approaches (according to [164]). Annotations: BS: basic symptoms; COPER: cognitive-perceptive basic symptoms; COGDIS: cognitive disturbances; APS: attenuated psychotic symptoms; BLIPS: brief limited intermittent psychotic symptoms; DUP: duration of untreated psychosis; DUI: duration of untreated illness.

psychoses impedes the identification of a disorder by patients and healthcare professionals. Thus, since the 1990s, efforts have increasingly focused on detecting and treating FEP early, preferably, in terms of indicated prevention, while the patient is still within the prodromal state and before the onset of persisting positive psychotic symptoms (Figure 1) [18-20].

As an example of these efforts, the present outlook paper will summarize the research conducted by the two authors, both being experts in this area of research, and their perspectives on it and conclude with an outlook on future questions that will have to be addressed.

\section{The First Episode of Psychoses}

2.1. The Melbourne Early Psychosis Prevention and Intervention Centre (EPPIC). The Early Psychosis Prevention and Intervention Centre (EPPIC) in Melbourne has been one of the first programmes with a mandate to detect and treat all patients with FEP of both early and young adult onset (midteens to midtwenties) [21]. Gradually developing between 1984 and 1992, EPPIC services a sector with a population of about 800,000 people. Working within a national mental health system, it receives all referrals with suspicion of a FEP. Thus, its database provides a unique and, in terms of sampling, unbiased opportunity to analyse the characteristics and treatment outcomes of all types of FEP [22-30] and has a special focus on bipolar psychoses [23, 31, 32]. Such detailed knowledge is important for identifying obstacles to care and for detecting starting-points for early detection and intervention in FEP and has therefore been in the special focus of the work of Benno Schimmelmann.

2.1.1. The Early Course of First-Episode Psychosis. One important finding of the EPPIC data was that diagnostic stability over 18 months is high for first episodes of schizophrenic psychoses with few shifts from schizophrenia to other diagnoses. On the other hand, patients with a FEP diagnosis of schizophreniform or bipolar disorder were diagnostically unstable, with frequent shifts to other psychotic disorders, mainly schizophrenia, necessitating longitudinal reassessment of their diagnoses [33]. Thus, after their first episode, most psychoses had a poor outcome within the first 18 months with the frequency of the diagnosis of its most severe type, schizophrenia, increasing. Thereby, persistent substance use over the treatment period but not baseline substance use was associated with nonremission of psychotic symptoms after 18 months, even after controlling for many relevant predictors of outcome [34]. Similarly, persistent cannabis use but not cannabis use at baseline was a significant predictor of worse outcome in early-onset psychosis [35]. Additionally cannabis 
use disorders starting before age 14 seem to predict an earlier onset of psychosis [36]; an earlier onset, in turn, had been associated with a poorer outcome [16]. Thus, substance and in particular cannabis use seem to have differential and agerelated effects on the course of psychosis: accelerating the onset of psychosis in young psychosis-prone adolescents and corrupting the outcome of FEP in general, that is, across all age groups.

2.1.2. Treatment Compliance in First-Episode Psychosis. Adherence to treatment and medication is a significant problem in early psychosis. In the FEP cohort of EPPIC $(N=$ 661), 19\% never took the prescribed medication and $23 \%$ disengaged from the program despite significant efforts to keep patients engaged in treatment (such as assertive community treatment, specific crisis teams, and highly specialized case managers). Predictors of service disengagement and medication nonadherence or refusal were persistent substance use over the treatment period, a forensic history, and lack of family support [37, 38]. Those consistently refusing all medications from the outset were more likely to have a forensic history compared to those who became nonadherent later on [38]. Service disengagement was further predicted by moderate illness severity and a lack of significant treatment success until disengagement from both the entire sample and the adolescent subsample $[37,39]$.

2.1.3. Early-Onset and Adult Onset Psychosis. With regard to developmental peculiarities, the EPPIC cohort has provided a unique opportunity to assess differences between EOP and young adult onset psychosis (AOP; starting between ages 18 and 28). Due to EPPIC's focus on a young age range, about $19 \%$ of the sample was EOP patients (onset between 8.2 and 17.9 years). Compared to AOP patients, EOP had a slightly lower premorbid functioning and considerably longer duration of untreated psychosis (median 26.3 weeks in EOP compared to 8.7 weeks in AOP). Notably, the significantly longer DUP in EOP accounted for their worse course after controlling for type of psychosis, level of premorbid functioning, family support, and psychiatric history. No significant outcome differences including illness severity, global functioning, remission of positive symptoms, or employment status were detected between EOP and AOP [40, 41]. Hence the negative effects of DUI and DUP may be exacerbated in EOP. The treatment delay observed in EOP may be due to several factors, including the more pronounced neurodevelopmental and cognitive deficits, the insidious onset of less pronounced positive symptoms, and/or the atypical clinical picture of the beginning EOP_-potentially misinterpreted as "adolescent crisis" [40]. Furthermore, as the age of onset of symptoms seems to be earlier in adolescent cannabis users [42], early symptoms might also be mistaken as substance-induced. Thus, early detection and treatment of persons with the first signs of the disorder, which is currently regarded as a promising strategy in fighting the consequences of psychosis, may face different or additional challenges in EOP as compared to AOP.
2.2. The Hamburg Psychosis Early Detection and Intervention Project (PEDIC). Based on the EPPIC experience, the Psychosis Early Detection and Intervention Project (PEDIC) was implemented in Hamburg in 2003. One early research focus of PEDIC was on remission and recovery of symptoms, functioning, and subjective well-being in adults with FEP [43-45].

\subsubsection{Remission and Recovery in First-Episode Schizophrenia.} In a 3-year follow-up study of 392 never-treated patients with schizophrenia cared for within PEDIC, remission rates were $60 \%$ for symptoms, $45 \%$ for functional deficits, and $57 \%$ for subjective well-being; corresponding recovery rates were $52 \%, 35 \%$, and $44 \% ; 28 \%$ were in combined remission and $17 \%$ in combined recovery (fulfilling all remission or recovery criteria, resp.). Studies examining predictors of remission and functional outcome have shown that premorbid and baseline psychosocial functioning and good treatment response with symptom remission within the first 3 months are the best predictors of both [45-51]. These findings have important clinical implications whereby the low proportion of patients who met remission or recovery criteria clearly highlights the importance of making adaptations to treatment early on [45]. Furthermore, our studies suggested that measures of quality of life and subjective well-being should be assessed when measuring the outcome of psychotic disorders [52-54]. The patient's perspective and experience might be particularly important when it comes to assessment of the side effects of antipsychotics. Because objective and subjective side effects often differ and subjective impairment may be a stronger predictor of nonadherence than objective measures of the severity of side effects, assessing both objective and subjective side effects has been strongly recommended [54].

\subsubsection{Assertive Community Treatment in Schizophrenia-} Spectrum Disorders: The Access Trial. Despite all of the knowledge gained about moderators of outcome in FEP, a crucial, yet unresolved, question is how patients with psychotic disorders are optimally treated. In Hamburg, we constructed a comprehensive treatment model for patients with both first- and multiple-episode schizophrenia-spectrum disorders, the ACCESS model, which included assertive community treatment, specialized personnel, integration of specific treatment options for psychotic patients such as cognitive-behavioural psychotherapy, metacognitive training, and a general psychotherapeutic approach including techniques of open dialogue [55-57]. At 12 months, patients treated in the ACCESS program had better outcomes than those treated as usual in an integrated care setting without assertive community treatment, case management, or specialized personnel in terms of service engagement, symptoms, functioning, quality of life, and satisfaction with care. The additional treatment effect of the ACCESS program was clearly significant, and the costs of ACCESS were similar to treatment as usual; therefore inpatient days were significantly decreased while outpatient contacts were increased $[58,59]$. ACCESS was then translated into clinical practice and extended to bipolar psychotic disorders. The benefits of 
the ACCESS treatment model, particularly in terms of high service engagement and low hospitalization rates, remained stable over a 2-year period [60], yet their longer-term effects remain to be studied.

2.3. Getting There Even Earlier: Lessons from First-Episode Psychosis Research. Despite a broad range of efforts to improve the outcome of FEP but also of multiepisode psychosis, many patients continue to suffer from symptoms as well as poor functioning and quality of life. Thus, not only is the early identification of patients with manifest psychotic disorders important in order to reduce the DUP [41], but also the early detection of at-risk mental states (ARMS) is mandatory for the reduction of DUI and the burden of psychotic disorders in both adults [61] and children and adolescents [62-65].

\section{The At-Risk Mental State}

Since Kraepelin's description of dementia praecox more than a century ago [66], diagnosis, treatment, and studies of psychosis have focused mainly on its cardinal positive and negative symptoms. In the last two decades, however, the growing interest in prodromal or risk states of the illness has generated renewed interest in the early subclinical expressions and subtle, self-experienced changes in mentation that had already been observed by Kraepelin $[66,67]$.

Until the 1980s, scattered and mainly retrospective reports of the psychotic prodrome prevailed that led to the formulation of early developmental models of schizophrenia such as Conrad's [68] and Docherty's [69] staging models, both assuming a unidirectional mandatory pattern of symptom manifestation. These invariant models, however, could not be confirmed by retrospective data on the early course assessed on FEP patients in the Age, Beginning, Course $(\mathrm{ABC})$ study $[16,70]$, suggesting that the road to psychosis might not be a straight one but rather twisted with stops and returns being possible at any stage [71, 72]. Thus, not knowing where the road is leading when looking at it prospectively, there is common agreement in prospective research nowadays not to use the retrospectively defined term "prodrome" that would indicate that a certain outcome is inevitable but to emphasise the risk along with the only more or less probable outcome. To this end, several terms have been proposed that are often used and considered interchangeable, even if they originally related to distinct concepts or assessments. This fact has unfortunately created Babylonian speech confusion as well as heterogeneity and variance of findings $[73,74]$. In the following, the term "atrisk mental state" (ARMS) that is not linked to a specific operationalization or assessment is used when prospectively relating to a state which may be the prodrome of a FEP.

\subsection{Symptomatic Risk Criteria for First-Episode Psychosis.} For the indicated prevention of psychosis in help-seeking persons already suffering from first signs and symptoms of the emerging disorder, two approaches were developed in parallel [75]. Both approaches distinguish between affective and nonaffective psychotic disorders and nonpsychotic affective disorders [76, 77]: the basic symptom (BS) approach targeting the earliest possible specific risk symptoms by our Cologne group and the ultrahigh risk (UHR) approach targeting an imminent risk of psychosis with a conversion within the next 12 months by the Melbourne and New Haven groups of Patrick McGorry and Thomas McGlashan (Figure 1).

\subsubsection{Basic Symptom Criteria}

(1) The Basic Symptom Concept. Relating to early descriptions of prodromal changes by Mayer-Gross [78], the most thorough early description of subtle early symptoms has been provided within the framework of the BS concept $[20,71,79]$. BS are subtle, subjectively experienced subclinical disturbances in drive, stress tolerance, affect, thinking, speech, attention, body and sensory perception, and motor action [71]. These subjective symptoms were regarded as the earliest perceivable signs of the developing psychotic disorder and its neurobiological correlates-hence the term "basic" [20]. Although BS vary in their specificity for psychoses and can occur in nonpsychotic disorders to various degrees $[76,80,81]$, they are recognized nowadays mainly for their occurrence in initial prodromal states of psychoses including potential outpost syndromes (i.e., spontaneously remitting "prodrome-like" phases preceding the prodrome leading to frank psychosis; Figure 2). Yet, they are not restricted to the early states but are an integral part of the disorder and can occur in all states [80-82], that is, within the prodrome of FEP, within prodromal states of relapse, within residual states, and even within acute psychotic episodes; consequently, the assessment of BS can serve several clinical and scientific purposes (Figure 2).

By definition, BS are not evoked by substance misuse or somatic illness and differ from what is considered to be one's "normal" mental self [71]. Being subjective, they remain predominately private and apparent only to the affected person and are rarely directly observable to others but might be indirectly observed by a patient's self-initiated coping strategies in response to BS such as social withdrawal or other avoidance strategies. It is this emphasis on the subjective, selfexperienced character that distinguishes BS from (i) negative symptoms in terms of functional deficits observable to others and (ii) frank psychotic symptoms which are experienced by the patient as real and normal thoughts and feelings. The ability to experience BS with insight, however, often attenuates with progressive illness and emerging (attenuated) psychotic symptoms but is commonly restored upon remission [71].

(2) Assessment Instruments of Basic Symptoms. Two instruments for the binary assessment of presence or absence of BS were initially developed in concerted action [83]: a semistructured clinical interview, the Bonn Scale for the Assessment of Basic Symptoms (BSABS) [84, 85], and a selfreport questionnaire, the Frankfurt Complaint Questionnaire (FCQ) [86]. Nevertheless, the correspondence between BSABS and FCQ subscales was poor, indicating that the mode of assessment is a crucial factor in the evaluation of BS $[67,87]$. 


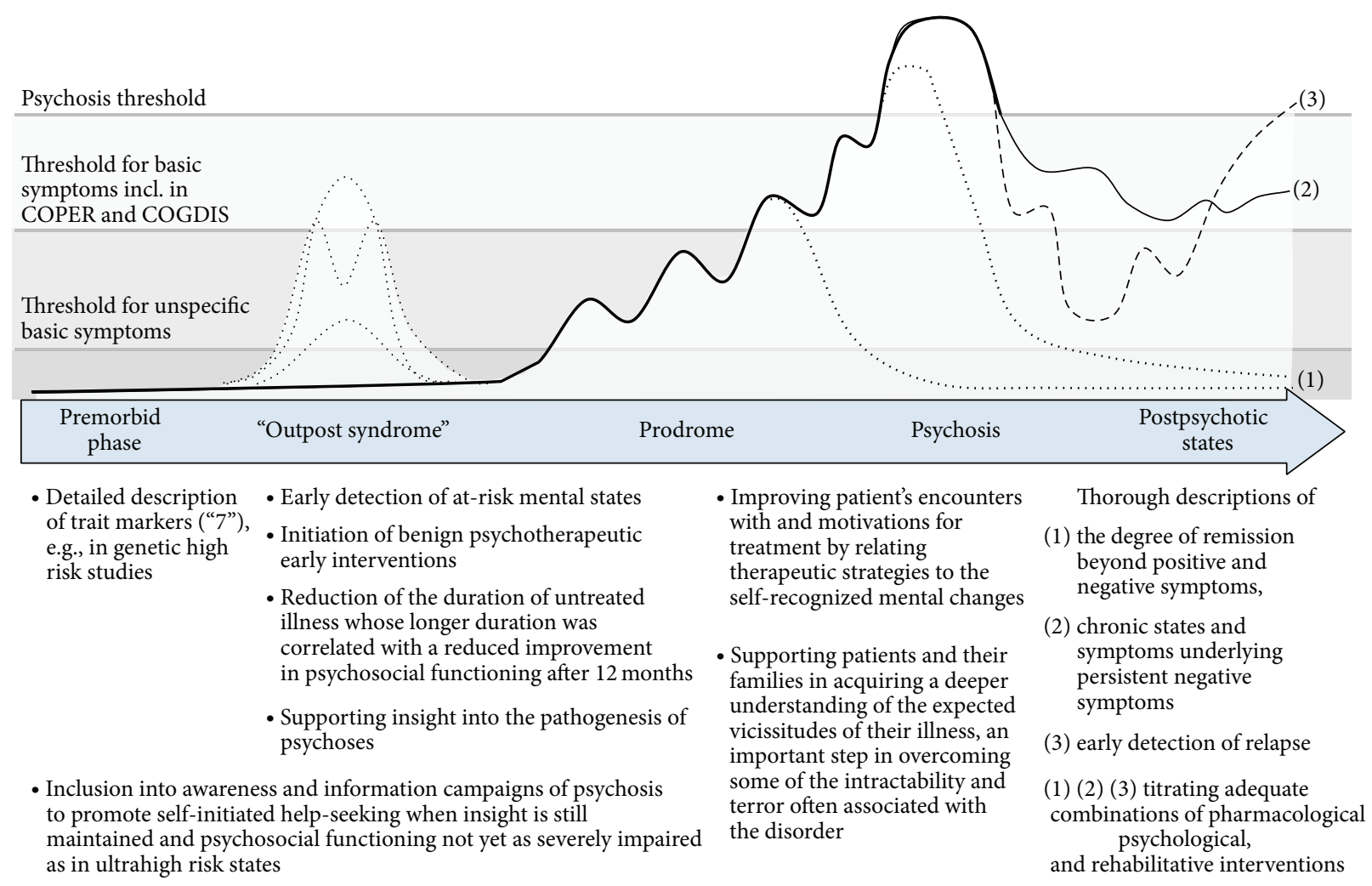

Figure 2: Range of possible applications of basic symptom assessment (according to [71, 91]). Annotation: (“7”): SPI-A/SPI-CY rating for basic symptom-like phenomena that are reported as having always been present in the current frequency in a trait-like manner.

Based on the BSABS, we developed an instrument for the quantitative clinical assessment of BS [67,88], that is, the Schizophrenia Proneness Instrument, in two versions, that is, an Adult (SPI-A; [89]) and a Child and Youth version (SPICY; $[90,91])$. With regard to the development of the SPI-A, the six BS dimensions in adult samples exhibited a robust structure across samples in different stages of the illness [88]. This structure even remained largely unchanged when BS assessment turned from the binary assessment of presence in the BSABS to an ordinal assessment of frequency-guided severity in the SPI-A. Yet, the structure could not be replicated in a sample of patients with nonpsychotic depressive disorders. Thus, it was concluded that these dimensions might be inherent and unique to schizophrenia and other psychoses and, therefore, can serve as valid and reliable subscales of an instrument for the assessment of BS [88]. Building on this, the final version of the SPI-A was developed after validation on a second prospectively assessed truly prodromal sample $[67,89]$. The SPI-A has shown good interrater reliability with an increase of the overall concordance rate with an expert rating from $60 \%$ to $89 \%$ across five training sessions $[67,89]$.

Though very consistent in adult samples, the sixdimensional structure of BS was absent in an EOP sample $[62,67]$. Rather, a four-dimensional structure was revealed that formed the basis for the subscales of the SPI-CY-thus far the only early detection instrument especially designed for use in children and adolescents aged 8 and older $[62,67,91]$.
A striking structural difference between the SPI-A and SPICY was that adynamic BS (e.g., lack of energy, motivation, drive, or (positive) feelings including sudden depressive mood, decreased stress tolerance, increased emotional responsiveness, and general cognitive impediments such as concentration, memory, and attention problems or reports of a "blank mind") appeared to play a central role in children and adolescents; this central position was held in adults by mainly cognitive BS, including those included in BS risk criteria described below [67]. The discriminative validity of the SPI-CY was preliminarily confirmed on three groups of children and adolescents: risk patients meeting UHR and/or BS criteria (AtRisk), clinical inpatient controls not suspected to be at risk for developing psychosis (ClinS), and children and adolescents from the general population (GPS) [92]. As expected, the groups differed significantly on all four SPICY subscales with the AtRisk sample scoring highest and the GPS lowest and at least moderate between-group effects that were largest for the subscale "Adynamia." However, these results require validation in a larger sample, and longitudinal studies should examine the psychosis-predictive ability of the subscales in different young age groups, especially the role of Adynamia. In cooperation with the Cologne and Zurich University Hospitals for Child and Adolescent Psychiatry, we are currently addressing these questions in a prospective study, the Binational Evaluation of At-Risk Symptoms in Children and Adolescents (BEARS-Kid) study, 
TABLE 1: At-risk criterion cognitive-perceptive basic symptoms (COPER) [89, 97].

Presence of at least any one of the following ten basic symptoms with at least weekly occurrence (i.e., a SPI-A/SPI-CY score of $\geq 3$ ) within the last three months and first occurrence at least 12 months ago (irrespective of frequency and persistence during this time):

(i) thought interference $(\mathrm{C} 2)^{\mathrm{a}}$

(ii) thought perseveration (O1)

(iii) thought pressure (D3)

(iv) thought blockages (C3)

(v) disturbance of receptive speech (C4)

(vi) decreased ability to discriminate between ideas and perception, fantasy and true memories (O2)

(vii) unstable ideas of reference (D4)

(viii) derealisation (O8)

(ix) visual perception disturbances, excl. blurred vision and hypersensitivity to light (D5, F2, F3, and O4)

(x) acoustic perception disturbances, excl. hypersensitivity to sounds (F5, O5)

${ }^{a}$ Item numbers refer to the SPI-A.

TABLE 2: High risk criterion cognitive disturbances (COGDIS) [89, 97].

Presence of at least any two of the following nine basic symptoms with at least weekly occurrence (i.e., a SPI-A/SPI-CY score of $\geq 3$ ) within the last three months:

(i) inability to divide attention $(\mathrm{B} 1)^{\mathrm{a}}$

(ii) thought interference $(\mathrm{C} 2)$

(iii) thought pressure (D3)

(iv) thought blockages (C3)

(v) disturbance of receptive speech (C4)

(vi) disturbance of expressive speech (C5)

(vii) unstable ideas of reference (D4)

(viii) disturbances of abstract thinking (O3)

(ix) captivation of attention by details of the visual field (O7)

${ }^{\mathrm{a}}$ Item numbers refer to the SPI-A.

which is funded by a common grant of the Swiss National Science Foundation and the German Research Foundation and examines four groups of altogether 800 children and adolescents (e.g., patients meeting ARMS criteria, inpatients with no clinical suspicion of an ARMS, patients with an EOP, and children and adolescents of the general population) for three years [http://p3.snf.ch/project-144100].

(3) The Basic Symptom Criteria for an At-Risk Mental State. The Cologne Early Recognition (CER) study [67, 85, 9395] was the first ever long-term naturalistic prospective early detection study with a mean follow-up period of 9.6 years and investigated the psychosis-predictive accuracy of BS assessed with the BSABS in 160 adult patients clinically suspected to be at risk for schizophrenia. Based on different types of analyses, two BS criteria that share some of the included BS were developed from its data [67, 85, 93-95]: "cognitiveperceptive basic symptoms" (COPER; Table 1) and "cognitive disturbances" (COGDIS; Table 2).

Compared to COPER, COGDIS seem to have a higher specificity, that is, are associated with higher conversion rates (Table 3), yet this might be at the cost of sensitivity, that is, related to missing more patients who are in fact about to develop a FEP [67]. In other words, COGDIS performed better in ruling in conversion to psychosis (moderate positive diagnostic likelihood ratio of 3.9), while COPER performed better in ruling it out (moderate negative diagnostic likelihood ratio of 0.23 ) $[93,96]$. Thus, in terms of a clinical staging, these BS criteria were thought to be possibly able to serve different clinical purposes in adult samples, that is, broad risk detection and symptom monitoring based on COPER versus risk detection with the intention to initiate specific psychosis-preventive treatment by COGDIS [93].

Subsequent studies by our group [97-100] and others $[101,102]$ confirmed the psychosis-predictive ability of both COPER and COGDIS, although conversion rates were somewhat lower at comparable follow-ups (Table 3). This decline might be caused by conservatively accounting for drop-outs as nonconverters [97-100], exclusion of symptomatic UHR criteria [98], age-related peculiarities [102], or other factors related to changes in referral and treatment practice that had been discussed in relation to the much more severe decline in conversion rates observed in UHR samples [103]. In addition, differences in conversion rates might also be related to differences in the BS composition of samples. Analyses of converters of the CER study with different duration of the prodrome defined as short ( $<1$ year), medium (1-6 years), and long ( $>6$ years) revealed group differences particularly in 
TABLE 3: Conversion rates for COPER and COGDIS in (sub)samples not systematically treated for psychosis-risk.

\begin{tabular}{|c|c|c|c|c|c|c|}
\hline \multirow{2}{*}{ Study } & \multirow{2}{*}{$\begin{array}{l}\text { BS criterion, } N \text { ( } N \text { criterion positive), predominant age } \\
\text { group, } n(\%) \text { lost-to-last-follow-up of total sample }\end{array}$} & \multicolumn{5}{|c|}{ Conversion rate at month } \\
\hline & & 12 & 18 & 24 & 36 & $>36$ \\
\hline \multirow{2}{*}[93,95]{} & COPER, 160 (106), adults, n.a. & $20 \%$ & & $37 \%$ & $50 \%$ & $65 \%^{\mathrm{c}}$ \\
\hline & COGDIS, 160 (67), adults, n.a. & $24 \%$ & & $46 \%$ & $61 \%$ & $79 \%^{\mathrm{c}}$ \\
\hline \multirow{2}{*}{ [97] } & COPER, $146(146)$, adults, $60(41 \%)^{b}$ & $25 \%$ & & $33 \%$ & & \\
\hline & COGDIS, $146(124)$, adults, $60(41 \%)^{\mathrm{b}}$ & $25 \%$ & & $33 \%$ & & \\
\hline$[98]^{\mathrm{a}}$ & COPER, $128(64)$, adults, $23(36 \%)^{\mathrm{b}}$ & $17 \%$ & & $20 \%$ & & \\
\hline$[99,114]$ & COGDIS, 245 (171), adults, $62(25 \%)^{b}$ & $14 \%$ & $19 \%$ & & & \\
\hline$[101]$ & COGDIS, 73 (48), adults, n.a. & & & $25 \%$ & & \\
\hline [102] & COGDIS, $72(39)$, adolescents, $15(21 \%)^{\mathrm{b}}$ & & & $18 \%$ & & \\
\hline [100] & COGDIS, $246(158)$, adults, $56(23 \%)^{\mathrm{b}}$ & $23 \%$ & & $34 \%$ & $40 \%$ & $42 \%^{\mathrm{d}}$ \\
\hline
\end{tabular}

${ }^{a}$ Supportive counselling control condition only; conversion rate includes conversion to a late state, that is, development of APS or BLIPS.

${ }^{\mathrm{b}}$ Those lost-to-follow-up were conservatively regarded as nonconverters, symptomatic UHR criteria excluded.

${ }^{\mathrm{c}}$ Minimum of 60 months, maximum of 359 months.

${ }^{\mathrm{d}}$ Months 36 to 48 .

n.a.: not applicable; only patients with complete follow-up data were included.

cognitive BS constellations that could be interpreted in terms of differences in underlying deficits in information processes, that is, in bottom-up, top-down, or central integrative processes [104]. Because of the current lack of sufficiently long follow-up data, these etiological considerations still await confirmation in independent samples as well as examination in neurocognitive studies.

3.1.2. Combining Basic Symptom and Ultrahigh Risk Criteria. Initially developed independently of each other, BS and UHR criteria (Table 4) frequently cooccur and are increasingly applied together-first within our Cologne Early Recognition and Intervention Centre (FETZ), Europe's pioneer early detection service for adults in an ARMS [97, 100, 105, 106]. A combined approach was adopted and first operationalized within the German Research Network on Schizophrenia (GRNS) [107] as a clinical staging model [108, 109] distinguishing an early from a late risk state [110] (Figure 1): an early risk state was alternatively defined by COPER and the UHR state-trait criterion, and a late risk state was alternatively defined by attenuated psychotic symptoms (APS) and brief limited intermittent psychotic symptoms (BLIPS).

The sequence by which symptoms progress according to the clinical staging model for ARMS [107-111]-from unspecific mental problems via first BS of COPER and second APS to psychotic symptoms (Figure 1)-was supported on retrospective data of FEP inpatients [17]. Furthermore, both approaches exhibited good sensitivity in this sample: $79 \%$ of the sample reported COPER and 71\% APS, whereby 63\% reported both APS and COPER [17]. A rather large but not complete overlap between BS and UHR criteria was also apparent in other ARMS studies [97, 99-102, 105].

Moreover, the highest 18-month and 48-month conversion rates showed for the combination of COGDIS and UHR criteria (mainly APS) compared to either COGDIS or UHR criteria alone $[67,99,100]$. For example, within a 48 month follow-up [100], COPER and UHR criteria exclusive of each other revealed hazard rates of 0.23 and 0.28 . In line with the GRNS staging model, in the "only UHR" group, conversions occurred between months 1 and 8 , while in the “only COGDIS" group, conversions occurred after month 5 but continued throughout the follow-up thereafter. The combined group "COGDIS plus UHR" showed conversions throughout the 48 months at a hazard rate of 0.66 . Notably, irrespective of each other both COGDIS and UHR showed an equal but lower hazard rate of 0.56 [100].

These findings support the merits of considering both COGDIS and UHR criteria in the early detection of persons who are at high clinical risk of developing a FEP; the combination with COPER has not yet been explicitly studied. Applying both sets of criteria improves the sensitivity of risk detection and the individual risk estimation; it may thereby support the development of stage-targeted interventions. Moreover, since the combination of COGDIS and UHR criteria enables the identification of considerably more homogeneous ARMS samples, it should support both preventive and basic research [100]. However, for the still considerable number of false-positive predictions, potential additional predictors enhancing the overall predictive accuracy-ideally without simultaneously reducing sensitivity-continue to be studied at all levels.

3.2. Searching for Additional Predictors to Enhance Predictive Accuracy. Across early detection studies, the addition of predictors frequently raised specificity at the cost of sensitivity, that is, frequently leading to a higher rate of exclusion of truly prodromal patients from preventive measures [112]. A possible solution to this dilemma, well-established in somatic medicine, is risk stratification [112, 113]. Risk stratification was first introduced in psychiatric prevention research within the European Prediction of Psychosis Study (EPOS) $[99,114]$, which used COGDIS and UHR criteria as assessed with the Structured Interview for Psychosis-Risk Syndromes (SIPS; [115]) to detect mainly adult ARMS patients. Examining additional psychopathological predictors, four risk classes for the 18-month conversion risk were identified based on a prognostic index calculated from APS severity, sleep disturbances, schizotypal personality disorder, and functioning and educational level [28]. Notably, the highest risk class contained a much higher percentage $(83 \%)$ of persons reporting both 
TABLE 4: Ultrahigh risk criteria according to the Structured Interview for Psychosis-Risk Syndromes (SIPS) [115].

"Brief limited intermittent psychotic symptom" (BLIPS) syndrome

(i) At least any 1 of the following SIPS P-items scored 6 "severe and psychotic":

(a) P1 unusual thought content/delusional ideas ${ }^{\mathrm{a}}$

(b) P2 suspiciousness/persecutory ideas

(c) P3 grandiose ideas

(d) P4 perceptual abnormalities/hallucinations

(e) P5 disorganized communication

(ii) First appearance in the past three months

(iii) Present for at least several minutes per day at a frequency of at least once per month but less than 7 days

"Attenuated psychotic symptom" (APS) syndrome ${ }^{\mathrm{b}}$

(i) At least any 1 of the following SIPS P-items scored 3 "moderate" to 5 "severe but not psychotic":

(a) P1 unusual thought content/delusional ideas

(b) P2 suspiciousness/persecutory ideas

(c) P3 grandiose ideas

(d) P4 perceptual abnormalities/hallucinations

(e) P5 disorganized communication

(ii) First appearance within the past year or current rating one or more scale points higher compared to 12 months ago

(iii) Symptoms have occurred at an average frequency of at least once per week in the past month

"Genetic risk and functional deterioration" (GRFD) syndrome

(1) Patient meets criteria for schizotypal personality disorder according to SIPS

(2) Patient has 1st degree relative with a psychotic disorder

(3) Patient has experienced at least 30\% drop in the global assessment of functioning (GAF) score over the last month compared to 12 months ago

[1 and 3] or [2 and 3] or all are met

${ }^{\mathrm{a}}$ Item numbers refer to the SIPS.

${ }^{b}$ In the definition of the Attenuated Psychosis Syndrome of DSM-5, requirements (i) to (iii) are complimented a fourth requirement; that is, significant disability or distress is caused by APS.

COGDIS and UHR criteria than all other risk classes (55$57 \%)$.

Other possible psychopathological predictors in adult samples were bipolar, somatoform, and unipolar depressive disorders at baseline, while anxiety disorders at baseline were negatively associated with conversion [116], the Strauss and Carpenter Prognostic Scale items assessing quality of useful work and social relations, positive symptoms and subjective distress [117], presence of ideas of reference and lack of close interpersonal relations as assessed with the Schizotypal Personality Questionnaire [118], and schizoid personality traits but neither schizotypal personality traits [119] nor dimensions of normal personality [120]. Together, these results point to an important role of functional deficits, especially in social contexts, high emotional responsiveness, and severity and persistence of APS in the development of psychosis in adult ARMS patients.

Another line of research on predictors has focussed on deficits in information processing that are common in FEP and have also been observed in ARMS patients, albeit to a lesser degree [121-124]. Objectively assessed neurocognitive deficits were widely independent of the subjectively reported cognitive disturbances included in COPER and COGDIS, thus offering the possibility to explain additional variance between ARMS patients who do or do not convert to psychosis [125]. Conversion was repeatedly related to processing speed deficits and lower premorbid verbal IQ, while results on the additional value of verbal memory deficits were conflicting $[126,127]$.

Similar to neurocognitive deficits, also electrophysiological abnormalities have been reported in both psychosis and adult ARMS patients with only slight differences [128, 129]. Abnormalities in mismatch negativity and quantitative EEG parameters have been associated with conversion [130, 131]. Another line of research, which evaluated biochemical abnormalities as potentially valuable predictors, found that anandamidergic upregulation might be a protector against conversion in ARMS patients [132, 133].

As many of these results have been generated independently of one another, future research should use large samples to ensure a sufficient number of converters so that simultaneous analyses of potential predictors and their interactions can be performed. In this way, nonredundant predictors that are most useful for a risk stratification of ARMS patients can be identified. Furthermore, while some of the potential predictors such as functional deficits, greater symptom severity, abnormalities in mismatch negativity, and processing speed deficits have already been replicated by other work groups (see [75] for overview), other results such as the protective role of an anandamidergic upregulation are still in need for replication in independent samples. And last but not least, all potential predictors still need to be studied for developmental differences in children and adolescent samples. 
3.3. Clinical Significance of the At-Risk Mental State. ARMS patients, however, not only are at risk for future psychosis but also are already suffering from a wide range of mental problems. In addition to the neurocognitive and electrophysiological abnormalities described above, they exhibit poor premorbid adjustment and deficits in psychosocial functioning and subjective quality of life that tend to worsen from the early to the late risk state [134-137]. Notably, a considerable number experience improvement in psychosocial outcome following the detection of an ARMS [138]. Furthermore, many ARMS patients suffer from other nonpsychotic mental disorders, frequently depression and anxiety $[105,116,139]$. Thus it was not surprising that the pattern of coping, self-efficacy, and control beliefs of ARMS patients closely resembled that of depressive patients in its frequent lack of positive coping strategies, low self-efficacy, and a fatalistic externalizing bias [140].

As we and others $[75,141]$ have shown that helpseeking ARMS samples are clinically significant, in 2008, we raised the question of whether current early detection approaches really target the "prodrome" of psychosis or rather a psychosis-spectrum disorder with a high risk for psychotic symptoms as one of the key questions in early detection research [142]. This issue became widely discussed a year later with the suggestion of including a psychosis-risk syndrome based on APS in DSM-5 [143]. In line with our rationale for a self-contained disorder [112, 144], this proposal was later revised to an APS-based self-contained disorder, the Attenuated Psychosis Syndrome [145]. As such, it was finally included in Section III of DSM-5 as a condition for future studies [146, 147]. Besides questions related to reliability, this decision was made for the unknown prevalence and clinical significance of such a syndrome outside help-seeking samples in the community [147].

3.4. Risk Criteria and Symptoms in the Community. The clinical significance of risk symptoms, in particular APS, outside help-seeking samples in the community had been called into question by the high prevalence rates reported for subclinical psychotic symptoms or psychotic-like experiences (PLEs) in the community. PLEs, however, have commonly been assessed by self-report questionnaires or layperson fully structured interviews and thus provide no valid measure of clinician-assessed APS or psychotic symptoms but significantly overestimate their prevalence [148]. Thus it was concluded that dedicated studies are warranted, in which APSand other risk criteria-are assessed in a way that equates to their clinical evaluation. Supported by a grant from the Swiss National Science Foundation and following confirmation of the reliability of telephone assessments of risk symptoms [149], we started such a study, the Bern Epidemiological AtRisk (BEAR) study, in 2011 (http://p3.snf.ch/project-135381). Both an interim analysis of the BEAR study and results from a proof-of-concept study $[150,151]$ confirmed our expectation that APS criteria and Attenuated Psychosis Syndrome are infrequent: they were met by less than $0.5 \%$ of the 1229 mainly adult interviewees that entered the interim analyses of the BEAR study. At symptom level, APS were reported by $13 \%$ of the sample and, indicating a clinical significance of APS in the community, were associated with functional impairments, current mental disorders, and help-seeking although they were not a reason for help-seeking [150]. Future analyses of the full sample of 16-40-year-olds after conclusion of the BEAR study in July 2014 will show if these results are maintained in a larger sample, while comparison with data with the 8-17-year-old community sample of the BEARS-Kid study will help to identify age-related peculiarities that were suggested by Kelleher et al. in their adolescent samples [152]. Furthermore, the aspired follow-up of the BEAR sample will reveal the course and impact of risk symptoms and criteria over time.

As regards BS criteria, COPER and COGDIS and their included BS were as equally rare as APS in the small proof-of-concept study [151], though further confirmation is needed from the larger sample queried in the BEAR study [150]. Furthermore, irrespective of their frequency, any one COPER-BS and any two COGDIS-BS were reported by only $8 \%$ and $3 \%$ of adolescents in the general population [153].

\section{Conclusion and Outlook}

For the lack of a significant breakthrough in the treatment of psychotic disorders after the onset of the first episode and due to the negative impact of the frequent and often years-long delays in the initiation of an adequate treatment on outcome, hopes are that indicated prevention of psychotic disorders in persons with first signs of the developing disorder will provide such a breakthrough $[61,75,109,154,155]$. To this end, an accurate and reliable early detection, that is, the development of exact, broadly applicable, and economic risk criteria, is a prerequisite.

Thus, the accuracy of prediction along with the safety of treatment has been in the main focus of critics and of, sometimes heated, ethical debates [156]. While further research is certainly needed, it is confronted with a dilemma of preventive research: with the growing awareness of the need for treatment in help-seeking ARMS patients and, consequently, its provision, the observation of the long-term natural course of potential risk symptoms that is necessary to develop accurate prediction models is increasingly impossible in clinical samples. The consideration of treatment effects as confounders in prediction analyses however not only raises the need for ever larger samples but also is hindered by the lack of knowledge about their long-term effectiveness [157, 158]. Yet a recent review reported a rather robust overall risk reduction across ten pharmacological and psychological early intervention studies at 12 months of $54 \%$ with a number-needed-to-treat of nine [159]. For this reason, longitudinal epidemiological studies that reliably and validly assess clinical risk criteria and symptoms in the general population become increasingly important, such as our BEAR study, the first epidemiological study on a large random representative sample of a broad age range and with a sufficient response rate of nearly $70 \%$ [150]. Such studies in unselected community samples might also help to alleviate fears about pathologising "normal" experiences that have been raised by reports on frequent and mostly benign PLEs in the community [147]. However, the benign PLEs measured 
by self-report in community samples may not be a valid measure of clinician-assessed symptoms [148]. Furthermore, community studies should increase knowledge about helpseeking to detect starting-points for increasing early helpseeking, because, at the currently low rate of only about $30 \%$ of FEP patients seeking help prior to the onset of frank psychotic symptoms $[13,14]$, a significant reduction of the incidence of psychosis - the ultimate target of preventionwill not be in sight. Another question that epidemiological research will help to address is whether to continue to regard current criteria as risk criteria with the main outcome being progression to psychosis and the main treatment target being its prevention or to rather perceive them as a self-contained syndrome in that remission, persistence, and progression, for example, to psychosis, are equally possible outcomes and in that the main treatment targets are current symptoms $[112,144]$. In both cases, however, the search for additional predictors of psychosis will continue.

Today, this search mainly relies on group differences that greatly depend on the studied sample and, consequently, are hard to transfer into clinical practice, that is, on the risk estimation of an individual patient [127, 140]. Thus, where available such as for neurocognitive or psychological tests, deficits should be defined according to independent test norms, and risk stratification approaches should be presented in a way acceptable to clinicians, that is, not as scores of a complex regression equation but as clear decision rules relying on certain patterns of aberrations [127, 160]. Such a presentation would also facilitate the validation of prediction rules in other samples. The use of norms that are generally already gender- and age-adjusted might also help to avoid heterogeneity in data related to gender and, more importantly, age effects that have just been started to be addressed in this line of research $[62-65,67,92,161,162]$, for example, by our multicentre BEARS-Kid study.

Age effects and needs of young age will also have to be considered in early intervention research in both ARMS and FEP patients, in particular with regard to more benign psychotherapeutic interventions [161]. Early interventions in an ARMS that have so far mainly focussed on risk symptoms and comorbidities $[155,157]$ might thereby broaden their focus to enhancing general resilience factors such as adequate coping strategies, metacognitive beliefs, or sleep [140, 163].

In summary, while exciting process has already been made in the field of early psychosis-both ARMS and FEPmuch remains to be done. And while psychosis research has traditionally been mainly carried out in general psychiatry and adult samples, research on early psychosis and, consequently, rather young patients calls for a stronger involvement of child and adolescent psychiatry and reconsideration of the often strict age-related separation of fields of responsibility of the two professions. A successful example is the FETZ Bern (http://www.fetz.gef.be.ch/fetz_gef/de/ index/navi/index.html), an early detection and intervention service that serves patients between the ages of 8 and $40-$ and, at this, the worldwide largest age range-and is run as a cooperation of the Bern University Hospitals for Child and Adolescent Psychiatry, and Psychiatry, and the Soteria Bern.

\section{Conflict of Interests}

Frauke Schultze-Lutter declares that there is no conflict of interests in relation to any subject of this paper. Benno G. Schimmelmann has been a consultant and/or advisor for or has received honoraria from Eli Lilly and Shire.

\section{Acknowledgments}

Studies presented in this paper were funded by the German Research Foundation, the Koeln Fortune Program/Faculty of Medicine (University of Cologne), the German Federal Ministry of Education and Health, the Swiss National Science Foundation, AstraZeneca (investigator initiated), Eli Lilly, Sanofi-Aventis, the Werner-Otto-Stiftung, and the National Health and Medical Research Council, Australia. Furthermore, many of the works presented in this paper would not have been possible without the support of the authors' respective earlier work groups and the cooperation of colleagues, of whom the authors would like to name Philippe Conus (Lausanne), Joachim Klosterkötter (Cologne), Martin Lambert (Hamburg), Patrick McGorry (Melbourne), Chantal Michel (Bern), and Stephan Ruhrmann (Cologne). SPI-A and SPI-CY are available in English and other languages at http://www.fioriti.it/.

\section{References}

[1] F. M. Gore, P. J. N. Bloem, G. C. Patton et al., "Global burden of disease in young people aged 10-24 years: a systematic analysis," The Lancet, vol. 377, no. 9783, pp. 2093-2102, 2011.

[2] J. Olesen and M. Leonardi, "The burden of brain diseases in Europe," European Journal of Neurology, vol. 10, no. 5, pp. 471477, 2003.

[3] J. Perälä, J. Suvisaari, S. I. Saarni et al., "Lifetime prevalence of psychotic and bipolar I disorders in a general population," Archives of General Psychiatry, vol. 64, no. 1, pp. 19-28, 2007.

[4] J. B. Kirkbride, P. Fearon, C. Morgan et al., "Heterogeneity in incidence rates of schizophrenia and other psychotic syndromes: findings from the 3-center ÆSOP study, Archives of General Psychiatry, vol. 63, no. 3, pp. 250-258, 2006.

[5] J. B. Kirkbride, C. Stubbins, and P. B. Jones, "Psychosis incidence through the prism of early intervention services," The British Journal of Psychiatry, vol. 200, no. 2, pp. 156-157, 2012.

[6] B. G. Schimmelmann, S. J. Schmidt, M. Carbon, and C. U. Correll, "Treatment of adolescents with early-onset schizophrenia spectrum disorders: in search of a rational, evidence-informed approach," Current Opinion in Psychiatry, vol. 26, no. 2, pp. 219230, 2013.

[7] H. U. Wittchen, F. Jacobi, J. Rehm et al., "The size and burden of mental disorders and other disorders of the brain in Europe 2010," European Neuropsychopharmacology, vol. 21, no. 9, pp. 655-679, 2011.

[8] A. Gustavsson, M. Svensson, F. Jacobi et al., "Cost of disorders of the brain in Europe 2010," European Neuropsychopharmacology, vol. 21, no. 10, pp. 718-779, 2011.

[9] N. Charrier, K. Chevreul, and I. Durand-Zaleski, "The cost of schizophrenia: a literature review," Encephale, vol. 39, supplement 1, pp. S49-S56, 2013. 
[10] M. Marshall, S. Lewis, A. Lockwood, R. Drake, P. Jones, and T. Croudace, "Association between duration of untreated psychosis and outcome in cohorts of first-episode patients: a systematic review," Archives of General Psychiatry, vol. 62, no. 9, pp. 975-983, 2005.

[11] M. S. Keshavan, G. Haas, J. Miewald et al., "Prolonged untreated illness duration from prodromal onset predicts outcome in first episode psychoses," Schizophrenia Bulletin, vol. 29, no. 4, pp. 757-769, 2003.

[12] D. Köhn, A. Niedersteberg, A. Wieneke et al., "Frühverlauf schizophrener Ersterkrankungen mit langer Dauer der unbehandelten Erkrankung-eine vergleichende Studie," Fortschr Neurol Psychiatr, vol. 72, no. 2, pp. 88-92, 2004.

[13] N. Schaffner, B. G. Schimmelmann, A. Niedersteberg, and F. Schultze-Lutter, "Versorgungswege von erstmanifesten psychotischen Patienten-eine Übersicht internationaler Studien," Fortschr Neurol Psychiatr, vol. 80, no. 2, pp. 72-78, 2012.

[14] D. Köhn, R. Pukrop, A. Niedersteberg et al., "Wege in die Behandlung: Hilfesuchverhalten schizophrener Ersterkrankter," Fortschr Neurol Psychiatr, vol. 72, no. 11, pp. 635-642, 2004.

[15] H. G. von Reventlow, S. Krüger-Özgürdal, S. Ruhrmann et al., "Pathways to care in subjects at high risk for psychotic disorders-a European perspective," Schizophrenia Research, vol. 152, no. 2-3, pp. 400-407, 2014.

[16] H. Hafner, B. Nowotny, W. Löffler, W. an der Heiden, and K. Maurer, "When and how does schizophrenia produce social deficits?" European Archives of Psychiatry and Clinical Neuroscience, vol. 246, no. 1, pp. 17-28, 1995.

[17] F. Schultze-Lutter, S. Ruhrmann, J. Berning, W. Maier, and J. Klosterkötter, "Basic symptoms and ultrahigh risk criteria: symptom development in the initial prodromal state," Schizophrenia Bulletin, vol. 36, no. 1, pp. 182-191, 2010.

[18] T. H. McGlashan and J. O. Johannessen, "Early detection and intervention with schizophrenia: rationale," Schizophrenia Bulletin, vol. 22, no. 2, pp. 201-222, 1996.

[19] P. D. McGorry, "A stitch in time... the scope for preventive strategies in early psychosis," European Archives of Psychiatry and Clinical Neuroscience, vol. 248, no. 1, pp. 22-31, 1998.

[20] G. Huber and G. Gross, "The concept of basic symptoms in schizophrenic and schizoaffective psychoses," Recenti Progressi in Medicina, vol. 80, no. 12, pp. 646-652, 1989.

[21] P. D. McGorry, J. Edwards, C. Mihalopoulos, S. M. Harrigan, and H. J. Jackson, "EPPIC: an evolving system of early detection and optimal management," Schizophrenia Bulletin, vol. 22, no. 2, pp. 305-326, 1996.

[22] P. Conus, S. Cotton, B. G. Schimmelmann, P. McGorry, and M. Lambert, "The First-episode Psychosis Outcome Study (FEPOS): pre-morbid and baseline characteristics of an epidemiological cohort of 661 first-episode psychosis patients," Early Intervention in Psychiatry, vol. 1, no. 2, pp. 191-200, 2007.

[23] P. Conus, S. Cotton, B. G. Schimmelmann, P. D. McGorry, and M. Lambert, "Pretreatment and outcome correlates of sexual and physical trauma in an epidemiological cohort of firstepisode psychosis patients," Schizophrenia Bulletin, vol. 36, no. 6, pp. 1105-1114, 2010.

[24] S. M. Cotton, M. Lambert, B. G. Schimmelmann et al., "Differences between first episode schizophrenia and schizoaffective disorder," Schizophrenia Research, vol. 147, no. 1, pp. 169-174, 2013.

[25] S. M. Cotton, M. Lambert, B. G. Schimmelmann et al., "Gender differences in premorbid, entry, treatment, and outcome characteristics in a treated epidemiological sample of 661 patients with first episode psychosis," Schizophrenia Research, vol. 114, no. 1-3, pp. 17-24, 2009.

[26] S. M. Cotton, M. Lambert, B. G. Schimmelmann et al., "Depressive symptoms in first episode schizophrenia spectrum disorder," Schizophrenia Research, vol. 134, no. 1, pp. 20-26, 2012.

[27] M. Lambert, P. Conus, B. G. Schimmelmann et al., "Comparison of olanzapine and risperidone in 367 first-episode patients with non-affective or affective psychosis: results of an open retrospective medical record study," Pharmacopsychiatry, vol. 38, no. 5, pp. 206-213, 2005.

[28] K. K. Morley, S. M. Cotton, P. Conus et al., "Familial psychopathology in the first episode psychosis outcome study," Australian and New Zealand Journal of Psychiatry, vol. 42, no. 7, pp. 617-626, 2008.

[29] S. Rebgetz, P. Conus, L. Hides et al., "Predictors of substance use reduction in an epidemiological first-episode psychosis cohort," Early Intervention in Psychiatry, vol. 24, pp. 1-24, 2013.

[30] J. Robinson, S. Cotton, P. Conus, B. G. Schimmelmann, P. McGorry, and M. Lambert, "Prevalence and predictors of suicide attempt in an incidence cohort of 661 young people with first-episode psychosis," Australian and New Zealand Journal of Psychiatry, vol. 43, no. 2, pp. 149-157, 2009.

[31] S. M. Cotton, M. Lambert, M. Berk et al., "Gender differences in first episode psychotic mania," BMC Psychiatry, vol. 13, no. 1, article 82, 2013.

[32] D. Schöttle, B. G. Schimmelmann, P. Conus et al., "Differentiating schizoaffective and bipolar I disorder in first-episode psychotic mania," Schizophrenia Research, vol. 140, no. 1-3, pp. 31-36, 2012.

[33] B. G. Schimmelmann, P. Conus, J. Edwards, P. D. McGorry, and M. Lambert, "Diagnostic stability 18 months after treatment initiation for first-episode psychosis," Journal of Clinical Psychiatry, vol. 66, no. 10, pp. 1239-1246, 2005.

[34] M. Lambert, P. Conus, D. I. Lubman et al., "The impact of substance use disorders on clinical outcome in 643 patients with first-episode psychosis," Acta Psychiatrica Scandinavica, vol. 112, no. 2, pp. 141-148, 2005.

[35] B. G. Schimmelmann, P. Conus, S. Cotton, S. Kupferschmid, P. D. McGorry, and M. Lambert, "Prevalence and impact of cannabis use disorders in adolescents with early onset first episode psychosis," European Psychiatry, vol. 27, no. 6, pp. 463469, 2012.

[36] B. G. Schimmelmann, P. Conus, S. M. Cotton et al., "Cannabis use disorder and age at onset of psychosis-a study in firstepisode patients," Schizophrenia Research, vol. 129, no. 1, pp. 5256, 2011.

[37] P. Conus, M. Lambert, S. Cotton, C. Bonsack, P. D. McGorry, and B. G. Schimmelmann, "Rate and predictors of service disengagement in an epidemiological first-episode psychosis cohort," Schizophrenia Research, vol. 118, no. 1-3, pp. 256-263, 2010.

[38] M. Lambert, P. Conus, S. Cotton, J. Robinson, P. D. McGorry, and B. G. Schimmelmann, "Prevalence, predictors, and consequences of long-term refusal of antipsychotic treatment in firstepisode psychosis," Journal of Clinical Psychopharmacology, vol. 30, no. 5, pp. 565-572, 2010.

[39] B. G. Schimmelmann, P. Conus, M. Schacht, P. McGorry, and M. Lambert, "Predictors of service disengagement in first-admitted adolescents with psychosis," Journal of the American Academy of Child and Adolescent Psychiatry, vol. 45, no. 8, pp. 990-999, 2006. 
[40] B. G. Schimmelmann, P. Conus, S. Cotton, P. D. McGorry, and M. Lambert, "Pre-treatment, baseline, and outcome differences between early-onset and adult-onset psychosis in an epidemiological cohort of 636 first-episode patients," Schizophrenia Research, vol. 95, no. 1-3, pp. 1-8, 2007.

[41] B. G. Schimmelmann, C. G. Huber, M. Lambert, S. Cotton, P. D. McGorry, and P. Conus, "Impact of duration of untreated psychosis on pre-treatment, baseline, and outcome characteristics in an epidemiological first-episode psychosis cohort," Journal of Psychiatric Research, vol. 42, no. 12, pp. 982-990, 2008.

[42] S. Dragt, D. H. Nieman, F. Schultze-Lutter et al., "Cannabis use and age at onset of symptoms in subjects at clinical high risk for psychosis," Acta Psychiatrica Scandinavica, vol. 125, no. 1, pp. 45-53, 2012.

[43] M. Lambert, A. Karow, S. Leucht, B. G. Schimmelmann, and D. Naber, "Remission in schizophrenia: validity, frequency, predictors, and patients' perspective 5 years later," Dialogues in Clinical Neuroscience, vol. 12, no. 3, pp. 393-407, 2010.

[44] M. Lambert, D. Naber, A. Karow et al., "Subjective wellbeing under quetiapine treatment: Effect of diagnosis, mood state, and anxiety," Schizophrenia Research, vol. 110, no. 1-3, pp. 7279, 2009.

[45] M. Lambert, D. Naber, A. Schacht et al., "Rates and predictors of remission and recovery during 3 years in 392 never-treated patients with schizophrenia," Acta Psychiatrica Scandinavica, vol. 118, no. 3, pp. 220-229, 2008.

[46] M. Lambert, B. G. Schimmelmann, D. Naber et al., "Early- and delayed antipsychotic response and prediction of outcome in 528 severely impaired patients with schizophrenia treated with amisulpride," Pharmacopsychiatry, vol. 42, no. 6, pp. 277-283, 2009.

[47] M. Lambert, B. G. Schimmelmann, A. Schacht et al., "Longterm patterns of subjective wellbeing in schizophrenia: Cluster, predictors of cluster affiliation, and their relation to recovery criteria in 2842 patients followed over 3 years," Schizophrenia Research, vol. 107, no. 2-3, pp. 165-172, 2009.

[48] M. Lambert, D. Naber, F. X. Eich, M. Schacht, M. Linden, and B. G. Schimmelmann, "Remission of severely impaired subjective wellbeing in 727 patients with schizophrenia treated with amisulpride," Acta Psychiatrica Scandinavica, vol. 115, no. 2, pp. 106-113, 2007.

[49] M. Lambert, B. G. Schimmelmann, D. Naber et al., "Prediction of remission as a combination of symptomatic and functional remission and adequate subjective well-being in 2960 patients with schizophrenia," The Journal of Clinical Psychiatry, vol. 67, no. 11, pp. 1690-1697, 2006.

[50] H. Meng, B. G. Schimmelmann, B. Mohler et al., "Pretreatment social functioning predicts 1-year outcome in early onset psychosis," Acta Psychiatrica Scandinavica, vol. 114, no. 4, pp. 249256, 2006.

[51] P. M. Wehmeier, M. Kluge, A. Schacht et al., "Patterns of physician and patient rated quality of life during antipsychotic treatment in outpatients with schizophrenia," Journal of Psychiatric Research, vol. 42, no. 8, pp. 676-683, 2008.

[52] B. G. Schimmelmann, C. Mehler-Wex, M. Lambert et al., "A prospective 12-week study of quetiapine in adolescents with schizophrenia spectrum disorders," Journal of Child and Adolescent Psychopharmacology, vol. 17, no. 6, pp. 768-778, 2007.

[53] A. Karow, J. Czekalla, R. W. Dittmann et al., "Association of subjective well-being, symptoms, and side effects with compliance after 12 months of treatment in schizophrenia," The Journal of Clinical Psychiatry, vol. 68, no. 1, pp. 75-80, 2007.
[54] B. G. Schimmelmann, S. Paulus, M. Schacht, C. Tilgner, M. Schulte-Markwort, and M. Lambert, "Subjective distress related to side effects and subjective well-being in first admitted adolescents with early-onset psychosis treated with atypical antipsychotics," Journal of Child and Adolescent Psychopharmacology, vol. 15, no. 2, pp. 249-258, 2005.

[55] M. Lambert, T. Bock, A. Daubmann et al., "Integrierte Versorgung von Patienten mit psychotischen Erkrankungen nach dem Hamburger Modell: Teil 1," Psychiatrische Praxis, vol. 41, no. 5, pp. 257-265, 2014.

[56] A. Karow, T. Bock, A. Daubmann et al., "Integrierte Versorgung von Patienten mit psychotischen Erkrankungen nach dem Hamburger Modell: Teil 2," Psychiatrische Praxis, vol. 41, no. 5, pp. 266-273, 2014.

[57] D. Schöttle, A. Karow, B. G. Schimmelmann, and M. Lambert, "Integrated care in patients with schizophrenia: results of trials published between 2011 and 2013 focusing on effectiveness and efficiency," Current Opinion in Psychiatry, vol. 26, no. 4, pp. 384408, 2013.

[58] M. Lambert, T. Bock, D. Schöttle et al., "Assertive community treatment as part of integrated care versus standard care: A 12-month trial in patients with first- and multipleepisode schizophrenia spectrum disorders treated with quetiapine immediate release (ACCESS trial)," Journal of Clinical Psychiatry, vol. 71, no. 10, pp. 1313-1323, 2010.

[59] A. Karow, J. Reimer, H. H. König et al., "Cost-effectiveness of 12-month therapeutic assertive community treatment as part of integrated care versus standard care in patients with schizophrenia treated with quetiapine immediate release (ACCESS trial)," Journal of Clinical Psychiatry, vol. 73, no. 3, pp. e402-e408, 2012.

[60] D. Schöttle, B. G. Schimmelmann, and A. Karow, "Translating Research into clinical practice: effectiveness of integrated care including therapeutic assertive community treatment in severe schizophrenia-spectrum and bipolar I disorders-a 24-month follow-up study (ACCESS-II study)," Journal of Clinical Psychiatry. In press.

[61] F. Schultze-Lutter, "Prediction of psychosis is necessary and possible," in Schizophrenia: Challenging the Orthodox, C. McDonald, K. Schultz, R. Murray, and P. Wright, Eds., pp. 8190, Taylor \& Francis, London, UK, 2004.

[62] E. Koch, F. Schultze-Lutter, B. G. Schimmelmann, and F. Resch, "On the importance and detection of prodromal symptoms from the perspective of child and adolescent psychiatry," Clinical Neuropsychiatry, vol. 7, no. 2, pp. 38-48, 2010.

[63] B. G. Schimmelmann, P. Walger, and F. Schultze-Lutter, "The significance of at-risk symptoms for psychosis in children and adolescents," Canadian Journal of Psychiatry, vol. 58, no. 1, pp. 32-40, 2013.

[64] B. G. Schimmelmann and F. Schultze-Lutter, "Early detection and intervention of psychosis in children and adolescents: urgent need for studies," European Child and Adolescent Psychiatry, vol. 21, no. 5, pp. 239-241, 2012.

[65] F. Schultze-Lutter, F. Resch, E. Koch, and B. G. Schimmelmann, "Früherkennung von Psychosen bei Kindern und Adoleszenten-sind entwicklungsbezogene Besonderheiten ausreichend berücksichtigt?" Zeitschrift für Kinder- und Jugendpsychiatrie und Psychotherapie, vol. 39, no. 5, pp. 301-311, 2011.

[66] E. Kraepelin, Psychiatrie. Ein Lehrbuch für Studierende und Ärzte. 8. vollständig umgearbeitete Auflage, Johann Ambrosius Barth, Leipzig, Germany, 1909. 
[67] F. Schultze-Lutter, S. Ruhrmann, P. Fusar-Poli, A. Bechdolf, B. G. Schimmelmann, and J. Klosterkötter, "Basic symptoms and the prediction of first-episode psychosis," Current Pharmaceutical Design, vol. 18, no. 4, pp. 351-357, 2012.

[68] K. Conrad, Die beginnende Schizophrenie. Versuch einer Gestaltanalyse des Wahns, Thieme, Stuttgart, Germany, 1958.

[69] J. P. Docherty, D. P. Van Kammen, S. G. Siris, and S. R. Marder, "Stages of onset of schizophrenic psychosis," The American Journal of Psychiatry, vol. 135, no. 4, pp. 420-426, 1978.

[70] H. Häfner, K. Maurer, W. Löffler, W. An der Heiden, M. Hambrecht, and F. Schultze-Lutter, "Modeling the early course of schizophrenia," Schizophrenia Bulletin, vol. 29, no. 2, pp. 325340, 2003.

[71] F. Schultze-Lutter, "Subjective symptoms of schizophrenia in research and the clinic: the basic symptom concept," Schizophrenia Bulletin, vol. 35, no. 1, pp. 5-8, 2009.

[72] A. R. Yung and P. O. McGorry, "The prodromal phase of first-episode psychosis: Past and current conceptualizations," Schizophrenia Bulletin, vol. 22, no. 2, pp. 353-370, 1996.

[73] F. Schultze-Lutter, B. G. Schimmelmann, and S. Ruhrmann, "The near babylonian speech confusion in early detection of psychosis," Schizophrenia Bulletin, vol. 37, no. 4, pp. 653-655, 2011.

[74] F. Schultze-Lutter, B. G. Schimmelmann, S. Ruhrmann, and C. Michel, "A rose is a rose is a rose, but at-risk criteria differ," Psychopathology, vol. 46, no. 2, pp. 75-87, 2013.

[75] P. Fusar-Poli, S. Borgwardt, A. Bechdolf et al., "The psychosis high-risk state: a comprehensive state-of-the-art review," JAMA Psychiatry, vol. 70, no. 1, pp. 107-120, 2013.

[76] F. Schultze-Lutter, S. Ruhrmann, H. Picker, H. G. von Reventlow, A. Brockhaus-Dumke, and J. Klosterkötter, "Basic symptoms in early psychotic and depressive disorders," British Journal of Psychiatry, vol. 191, supplement 51, pp. S31-S37, 2007.

[77] F. Schultze-Lutter, B. G. Schimmelmann, J. Klosterkötter, and S. Ruhrmann, "Comparing the prodrome of schizophreniaspectrum psychoses and affective disorders with and without psychotic features," Schizophrenia Research, vol. 138, no. 2-3, pp. 218-222, 2012.

[78] W. Mayer-Gross, "Die klinik," in Handbuch der Geisteskrankheiten-Spezieller Teil V: Die Schizophrenie, O. Bumke, Ed., Julius Springer, Berlin, Germany, 1932.

[79] G. Huber, "Reine Defektsyndrome und Basisstadien endogener Psychosen," Fortschritte der Neurologie-Psychiatrie, vol. 34, pp. 409-426, 1966.

[80] J. Klosterkotter, H. Ebel, F. Schultze-Lutter, and E. M. Steinmeyer, "Diagnostic validity of basic symptoms," European Archives of Psychiatry and Clinical Neuroscience, vol. 246, no. 3, pp. 147-154, 1996.

[81] F. Schultze-Lutter and J. Klosterkotter, "Do basic symptoms provide a possible explanation for the elevated risk for schizophrenia among mentally retarded?" Neurology Psychiatry and Brain Research, vol. 3, no. 1, pp. 29-34, 1995.

[82] A. Bechdolf, F. Schultze-Lutter, and J. Klosterkötter, "Selfexperienced vulnerability, prodromal symptoms and coping strategies preceding schizophrenic and depressive relapses," European Psychiatry, vol. 17, no. 7, pp. 384-393, 2002.

[83] L. Süllwold and G. Huber, Schizophrene Basisstörungen, Springer, Berlin, Germany, 1986.

[84] G. Gross, G. Huber, J. Klosterkötter, and M. Linz, Bonner Skala für die Beurteilung von Basissymptomen (BSABS; Bonn Scale for the Assessment of Basic Symptoms), Springer, Berlin, Germany, 1987.
[85] J. Klosterkötter, G. Gross, G. Huber, A. Wieneke, E. M. Steinmeyer, and F. Schultze-Lutter, "Evaluation of the "bonn scale for the assessment of basic symptoms-BSABS" as an instrument for the assessment of schizophrenia proneness: a review of recent findings," Neurology, Psychiatry and Brain Research, vol. 5, no. 3, pp. 137-150, 1997.

[86] L. Süllwold, Manual Zum Frankfurter Beschwerde-Fragebogen (FBF), Springer, Berlin, Germany, 1991.

[87] R. Mass, K. Hitschfeld, E. Wall, and H. B. Wagner, "Validität der Erfassung schizophrener Basissymptome," Nervenarzt, vol. 68, no. 3, pp. 205-211, 1997.

[88] F. Schultze-Lutter, E. M. Steinmeyer, S. Ruhrmann, and J. Klosterkötter, "The dimensional structure of self-reported prodromal disturbances in schizophrenia," Clinical Neuropsychiatry, vol. 5, no. 3, pp. 140-150, 2008.

[89] F. Schultze-Lutter, J. Addington, S. Ruhrmann, and J. Klosterkötter, Schizophrenia Proneness Instrument-Adult Version (SPI-A), Giovanni Fioriti Editore, Rome, Italy, 2007.

[90] F. Schultze-Lutter and E. Koch, Schizophrenia Proneness Instrument-Child and Youth Version (SPI-CY), Giovanni Fioriti Editore, Rome, Italy, 2010.

[91] F. Schultze-Lutter, M. Marshall, and E. Koch, Schizophrenia Proneness Instrument, Child and Youth Version, Extended English Translation (SPI-CY EET), Giovanni Fioriti Editore, Rome, Italy, 2012.

[92] L. Fux, P. Walger, B. G. Schimmelmann, and F. Schultze-Lutter, "The schizophrenia proneness instrument, child and youth version (SPI-CY): practicability and discriminative validity," Schizophrenia Research, vol. 146, no. 1-3, pp. 69-78, 2013.

[93] F. Schultze-Lutter, S. Ruhrmann, and J. Klosterkötter, "Can schizophrenia be predicted phenomenologically?" in Evolving Psychosis. Different Stages, Different Treatments, J. O. Johannessen, B. Martindale, and J. Cullberg, Eds., pp. 104-123, Routledge, London, UK, 2010.

[94] M. Albers, F. Schultze-Lutter, E. M. Steinmeyer, and J. Klosterkötter, "Can self-experienced neuropsychological deficits indicate propensity to schizophrenic psychosis? Results of an 8-year prospective follow-up study," International Clinical Psychopharmacology, vol. 13, supplement 1, pp. S75-S80, 1998.

[95] J. Klosterkötter, M. Hellmich, E. M. Steinmeyer, and F. SchultzeLutter, "Diagnosing schizophrenia in the initial prodromal phase," Archives of General Psychiatry, vol. 58, no. 2, pp. 158-164, 2001.

[96] F. Schultze-Lutter, "Ruling in or ruling out the schizophrenic prodrome: what criteria for symptom selection should be used?" Schizophrenia Research, vol. 41, no. 1, p. 179, 2000.

[97] F. Schultze-Lutter, J. Klosterkötter, H. Picker, E.-M. Steinmeyer, and S. Ruhrmann, "Predicting first-episode psychosis by basic symptom criteria," Clinical Neuropsychiatry, vol. 4, no. 1, pp. 1122, 2007.

[98] A. Bechdolf, M. Wagner, S. Ruhrmann et al., "Preventing progression to first-episode psychosis in early initial prodromal states," The British Journal of Psychiatry, vol. 200, no. 1, pp. 2229, 2012.

[99] S. Ruhrmann, F. Schultze-Lutter, R. K. R. Salokangas et al., "Prediction of psychosis in adolescents and young adults at high risk: results from the prospective European prediction of psychosis study," Archives of General Psychiatry, vol. 67, no. 3, pp. 241-251, 2010. 
[100] F. Schultze-Lutter, J. Klosterkötter, and S. Ruhrmann, "Improving the clinical prediction of psychosis by combining ultrahigh risk criteria and cognitive basic symptoms," Schizophrenia Researc, vol. 154, no. 1-3, pp. 100-106, 2014.

[101] E. Velthorst, D. H. Nieman, H. E. Becker et al., "Baseline differences in clinical symptomatology between ultra high risk subjects with and without a transition to psychosis," Schizophrenia Research, vol. 109, no. 1-3, pp. 60-65, 2009.

[102] T. B. Ziermans, P. F. Schothorst, M. Sprong, and H. van Engeland, "Transition and remission in adolescents at ultrahigh risk for psychosis," Schizophrenia Research, vol. 126, no. 1-3, pp. 58-64, 2011.

[103] A. R. Yung, H. P. Yuen, G. Berger et al., "Declining transition rate in ultra high risk (prodromal) services: dilution or reduction of risk?" Schizophrenia Bulletin, vol. 33, no. 3, pp. 673-681, 2007.

[104] F. Schultze-Lutter, S. Ruhrmann, C. Hoyer, J. Klosterkötter, and F. M. Leweke, "The initial prodrome of schizophrenia: different duration, different underlying deficits?" Comprehensive Psychiatry, vol. 48, no. 5, pp. 479-488, 2007.

[105] F. Schultze-Lutter, S. Ruhrmann, and J. Klosterkötter, "Early detection of psychosis-establishing a service for persons at risk," European Psychiatry, vol. 24, no. 1, pp. 1-10, 2009.

[106] F. Schultze-Lutter, S. Ruhrmann, and J. Klosterkötter, "Early detection and early intervention in psychosis in Western Europe," Clinical Neuropsychiatry, vol. 5, no. 6, pp. 303-315, 2008.

[107] H. Häfner, K. Maurer, S. Ruhrmann et al., "Early detection and secondary prevention of psychosis: facts and visions," European Archives of Psychiatry and Clinical Neuroscience, vol. 254, no. 2, pp. 117-128, 2004.

[108] J. Klosterkötter, "The clinical staging and the endophenotype approach as an integrative future perspective for psychiatry," World Psychiatry, vol. 7, no. 3, pp. 159-160, 2008.

[109] J. Klosterkötter, F. Schultze-Lutter, and S. Ruhrmann, "Prediction and prevention of schizophrenia: what has been achieved and where to go next?" World Psychiatry, vol. 10, no. 3, pp. 165174, 2011.

[110] S. Ruhrmann, F. Schultze-Lutter, and J. Klosterkötter, "Early detection and intervention in the initial prodromal phase of schizophrenia," Pharmacopsychiatry, vol. 36, supplement 3, pp. S162-S167, 2003.

[111] J. Klosterkötter, F. Schultze-Lutter, and S. Ruhrmann, "Kraepelin and psychotic prodromal conditions," European Archives of Psychiatry and Clinical Neuroscience, vol. 258, no. 2, pp. 7484, 2008.

[112] S. Ruhrann, F. Schultze-Lutter, and J. Klosterkötter, "Subthreshold states of psychosis-a challenge to diagnosis and treatment," Clinical Neuropsychiatry, vol. 7, no. 2, pp. 72-87, 2010.

[113] J. T. Bigger Jr., C. A. Heller, T. L. Wenger, and F. M. Weld, "Risk stratification after acute myocardial infarction," The American Journal of Cardiology, vol. 42, no. 2, pp. 202-210, 1978.

[114] J. Klosterkötter, S. Ruhrmann, F. Schultze-Lutter et al., “ The European prediction of psychosis study (EPOS): integrating early recognition and intervention in Europe," World Psychiatry, vol. 4, no. 3, pp. 161-167, 2005.

[115] T. H. McGlashan, B. C. Walsh, and S. W. Woods, The PsychosisRisk Syndrome, Oxford University Press, New York, NY, USA, 2010.
[116] R. K. R. Salokangas, S. Ruhrmann, H. G. von Reventlow et al., "Axis I diagnoses and transition to psychosis in clinical highrisk patients EPOS project: Prospective follow-up of 245 clinical high-risk outpatients in four countries," Schizophrenia Research, vol. 138, no. 2-3, pp. 192-197, 2012.

[117] D. H. Nieman, E. Velthorst, H. E. Becker et al., "The Strauss and Carpenter Prognostic Scale in subjects clinically at high risk of psychosis," Acta Psychiatrica Scandinavica, vol. 127, no. 1, pp. 5361, 2013.

[118] R. K. R. Salokangas, P. Dingemans, M. Heinimaa et al., "Prediction of psychosis in clinical high-risk patients by the Schizotypal Personality Questionnaire. Results of the EPOS project," European Psychiatry, vol. 28, no. 8, pp. 469-475, 2013.

[119] F. Schultze-Lutter, J. Klosterkötter, C. Michel, K. Winkler, and S. Ruhrmann, "Personality disorders and accentuations in at-risk persons with and without conversion to first-episode psychosis," Early Intervention in Psychiatry, vol. 6, no. 4, pp. 389-398, 2012.

[120] F. Schultze-Lutter, J. Klosterkötter, A. Nikolaides, and S. Ruhrmann, "Personality dimensions in subjects symptomatically at-risk of psychosis: pronounced but lacking a characteristic profile," Early Intervention in Psychiatry, 2014.

[121] R. Pukrop, F. Schultze-Lutter, S. Ruhrmann et al., "Neurocognitive functioning in subjects at risk for a first episode of psychosis compared with first- and multiple-episode schizophrenia," Journal of Clinical and Experimental Neuropsychology, vol. 28, no. 8, pp. 1388-1407, 2006.

[122] E. Gouzoulis-Mayfrank, M. Balke, S. Hajsamou et al., "Orienting of attention in unmedicated patients with schizophrenia, prodromal subjects and healthy relatives," Schizophrenia Research, vol. 97, no. 1-3, pp. 35-42, 2007.

[123] D. Koethe, C. W. Gerth, M. A. Neatby et al., "Disturbances of visual information processing in early states of psychosis and experimental delta-9-tetrahydrocannabinol altered states of consciousness," Schizophrenia Research, vol. 88, no. 1-3, pp. 142-150, 2006.

[124] D. Koethe, L. Kranaster, C. Hoyer et al., "Binocular depth inversion as a paradigm of reduced visual information processing in prodromal state, antipsychotic-naïve and treated schizophrenia," European Archives of Psychiatry and Clinical Neuroscience, vol. 259, no. 4, pp. 195-202, 2009.

[125] F. Schultze-Lutter, S. Ruhrmann, H. Picker et al., "Relationship between subjective and objective cognitive function in the early and late prodrome," The British Journal of Psychiatry, vol. 191, supplement 51, pp. s43-s51, 2007.

[126] R. Pukrop, S. Ruhrmann, F. Schultze-Lutter, A. Bechdolf, A. Brockhaus-Dumke, and J. Klosterkötter, "Neurocognitive indicators for a conversion to psychosis: comparison of patients in a potentially initial prodromal state who did or did not convert to a psychosis," Schizophrenia Research, vol. 92, no. 13, pp. 116-125, 2007.

[127] C. Michel, S. Ruhrmann, B. G. Schimmelmann, J. Klosterkötter, and F. Schultze-Lutter, "A stratified model for psychosis prediction in clinical practice," Schizophrenia Bulletin, 2014.

[128] A. Brockhaus-Dumke, I. Tendolkar, R. Pukrop, F. SchultzeLutter, J. Klosterkötter, and S. Ruhrmann, "Impaired mismatch negativity generation in prodromal subjects and patients with schizophrenia," Schizophrenia Research, vol. 73, no. 2-3, pp. 297310, 2005.

[129] A. Brockhaus-Dumke, F. Schultze-Lutter, R. Mueller et al., "Sensory gating in schizophrenia: P50 and N100 gating in antipsychotic-free subjects at risk, first-episode and chronic patients," Biological Psychiatry, vol. 64, no. 5, pp. 376-384, 2008. 
[130] M. J. van Tricht, S. Ruhrmann, M. Arns et al., "Can quantitative EEG measures predict clinical outcome in subjects at clinical high risk for psychosis? A prospective multicenter study," Schizophrenia Research, vol. 153, no. 1-3, pp. 42-47, 2014.

[131] M. Bodatsch, S. Ruhrmann, M. Wagner et al., "Prediction of psychosis by mismatch negativity," Biological Psychiatry, vol. 69, no. 10, pp. 959-966, 2011.

[132] J. T. Huang, F. M. Leweke, T. M. Tsang et al., "CSF metabolic and proteomic profiles in patients prodromal for psychosis," PLoS ONE, vol. 2, no. 8, article e756, 2007.

[133] D. Koethe, A. Giuffrida, D. Schreiber et al., "Anandamide elevation in cerebrospinal fluid in initial prodromal states of psychosis," British Journal of Psychiatry, vol. 194, no. 4, pp. 371372, 2009.

[134] A. Bechdolf, R. Pukrop, D. Köhn et al., "Subjective quality of life in subjects at risk for a first episode of psychosis: a comparison with first episode schizophrenia patients and healthy controls," Schizophrenia Research, vol. 79, no. 1, pp. 137-143, 2005.

[135] S. Ruhrmann, J. Paruch, A. Bechdolf et al., "Reduced subjective quality of life in persons at risk for psychosis," Acta Psychiatrica Scandinavica, vol. 117, no. 5, pp. 357-368, 2008.

[136] E. Velthorst, D. H. Nieman, D. Linszen et al., "Disability in people clinically at high risk of psychosis," The British Journal of Psychiatry, vol. 197, no. 4, pp. 278-284, 2010.

[137] R. K. R. Salokangas, M. Heinimaa, T. From et al., "Short-term functional outcome and premorbid adjustment in clinical highrisk patients. Results of the EPOS project," European Psychiatry, vol. 29, no. 6, pp. 371-380, 2014.

[138] R. K. R. Salokangas, D. H. Nieman, M. Heinimaa et al., "Psychosocial outcome in patients at clinical high risk of psychosis: a prospective follow-up," Social Psychiatry and Psychiatric Epidemiology, vol. 48, no. 2, pp. 303-311, 2013.

[139] F. Schultze-Lutter, H. Picker, S. Ruhrmann, and J. Klosterkötter, "Das Kölner Früh-Erkennungs- \& Therapie-Zentrum für psychische Krisen (FETZ)," Medizinische Klinik, vol. 103, no. 2, pp. 81-89, 2008.

[140] S. J. Schmidt, V. M. Grunert, B. G. Schimmelmann, F. SchultzeLutter, and C. Michel, "Differences in coping, self-efficacy, and external control beliefs between patients at-risk for psychosis and patients with first-episode psychosis," Psychiatry Research, vol. 219, no. 1, pp. 95-102, 2014.

[141] F. Schultze-Lutter and S. Ruhrmann, Früherkennung und Frühbehandlung von Psychosen, Uni-Med, Bremen, Germany, 2008.

[142] A. Grispini and F. Schultze-Lutter, "Introductory remarks to special issue: early detection and intervention in psychosis around the world," Clinical Neuropsychiatry, vol. 5, no. 5, article 261, 2008.

[143] S. W. Woods, J. Addington, K. S. Cadenhead et al., "Validity of the prodromal risk syndrome for first psychosis: findings from the north american prodrome longitudinal study," Schizophrenia Bulletin, vol. 35, no. 5, pp. 894-908, 2009.

[144] S. Ruhrmann, F. Schultze-Lutter, and J. Klosterkötter, "Probably at-risk, but certainly ill-advocating the introduction of a psychosis spectrum disorder in DSM-V," Schizophrenia Research, vol. 120, no. 1-3, pp. 23-37, 2010.

[145] W. T. Carpenter Jr., "Criticism of the DSM-V risk syndrome: a rebuttal," Cognitive Neuropsychiatry, vol. 16, no. 2, pp. 101-106, 2011.

[146] F. Schultze-Lutter and B. G. Schimmelmann, "Psychotische Störungen im DSM-5," Zeitschrift fur Kinder- und Jugendpsychiatrie und Psychotherapie, vol. 42, no. 3, pp. 193-202, 2014.
[147] A. R. Yung, S. W. Woods, S. Ruhrmann et al., "Whither the attenuated psychosis syndrome?" Schizophrenia Bulletin, vol. 38, no. 6, pp. 1130-1134, 2012.

[148] F. Schultze-Lutter, F. Renner, J. Paruch, D. Julkowski, J. Klosterkötter, and S. Ruhrmann, "Self-reported psychotic-like experiences are a poor estimate of clinician-rated attenuated and frank delusions and hallucinations," Psychopathology, vol. 47, no. 3, pp. 194-201, 2014.

[149] C. Michel, B. G. Schimmelmann, S. Kupferschmid, M. Siegwart, and F. Schultze-Lutter, "Reliability of telephone assessments of at-risk criteria of psychosis: a comparison to face-to-face interviews," Schizophrenia Research, vol. 153, no. 1-3, pp. 251253, 2014.

[150] F. Schultze-Lutter, C. Michel, S. Ruhrmann, and B. G. Schimmelmann, "Prevalence and clinical significance of DSM-5attenuated psychosis syndrome in adolescents and young adults in the general population: the bern epidemiological at-risk (BEAR) study," Schizophr Bull, 2013.

[151] B. G. Schimmelmann, C. Michel, N. Schaffner, and F. SchultzeLutter, "What percentage of people in the general population satisfies the current clinical at-risk criteria of psychosis?" Schizophrenia Research, vol. 125, no. 1, pp. 99-100, 2011.

[152] I. Kelleher, H. Keeley, P. Corcoran et al., "Clinicopathological significance of psychotic experiences in non-psychotic young people: evidence from four population-based studies," The British Journal of Psychiatry, vol. 201, no. 1, pp. 26-32, 2012.

[153] H. Meng, B. G. Schimmelmann, E. Koch et al., "Basic symptoms in the general population and in psychotic and non-psychotic psychiatric adolescents," Schizophrenia Research, vol. 111, no. 13, pp. 32-38, 2009.

[154] A. R. Yung, E. Killackey, S. E. Hetrick et al., "The prevention of schizophrenia," International Review of Psychiatry, vol. 19, no. 6, pp. 633-646, 2007.

[155] S. Ruhrmann, J. Klosterkötter, M. Bodatsch et al., "Chances and risks of predicting psychosis," European Archives of Psychiatry and Clinical Neuroscience, vol. 262, supplement 2, pp. 85-90, 2012.

[156] J. Klosterkötter and F. Schultze-Lutter, "Prevention and early treatment," in Ethics in Psychiatry-European Contributions, H. Helmchen and N. Sartorius, Eds., pp. 235-262, Springer Science+Business Media B.V., Heidelberg, The Netherlands, 2010.

[157] S. Ruhrmann, F. Schultze-Lutter, and J. Klosterkötter, "Intervention in the at-risk state to prevent transition to psychosis," Current Opinion in Psychiatry, vol. 22, no. 2, pp. 177-183, 2009.

[158] S. Ruhrmann, J. Klosterkötter, M. Bodatsch et al., "Pharmacological prevention and treatment in clinical at-risk states for psychosis," Current Pharmaceutical Design, vol. 18, no. 4, pp. 550-557, 2012.

[159] M. van der Gaag, F. Smit, A. Bechdolf et al., "Preventing a first episode of psychosis: meta-analysis of randomized controlled prevention trials of 12 month and longer-term follow-ups," Schizophrenia Research, vol. 149, no. 1-3, pp. 56-62, 2013.

[160] F. Schultze-Lutter, Früherkennung der Schizophrenie anhand subjektiver Beschwerdeschilderungen: ein methodenkritischer Vergleich der Vorhersageleistung nonparametrischer statistischer und alternativer Verfahren zur Generierung von Vorhersagemodelle [dissertation], Philosophical Faculty of the University of Cologne, 2001. 
[161] S. J. Schmidt and B. G. Schimmelmann, "Evidence-based psychotherapy in children and adolescents: advances, methodological and conceptual limitations, and perspectives," European Child \& Adolescent Psychiatry, vol. 22, no. 5, pp. 265-268, 2013.

[162] B. G. Schimmelmann, "Früherkennung von Psychosen Risiken und Nutzen bei Kindern und Jugendlichen abwägen," Zeitschrift für Kinder und Jugendpsychiatrie und Psychotherapie, vol. 39, no. 5, pp. 297-299, 2011.

[163] L. Tarokh, C. Hamann, and B. G. Schimmelmann, "Sleep in child and adolescent psychiatry: overlooked and underappreciated," European Child \& Adolescent Psychiatry, vol. 23, no. 6, pp. 369-372, 2014.

[164] F. Schultze-Lutter, "Früherkennung von psychosen vor deren erstmanifestation: chance oder sackgasse? Die kerbe," Forum für Sozialpsychiatrie, vol. 3, pp. 36-39, 2014. 


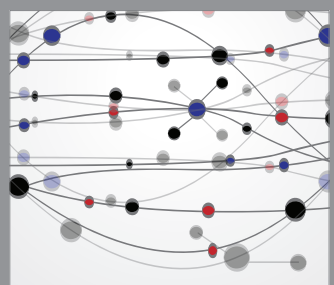

The Scientific World Journal
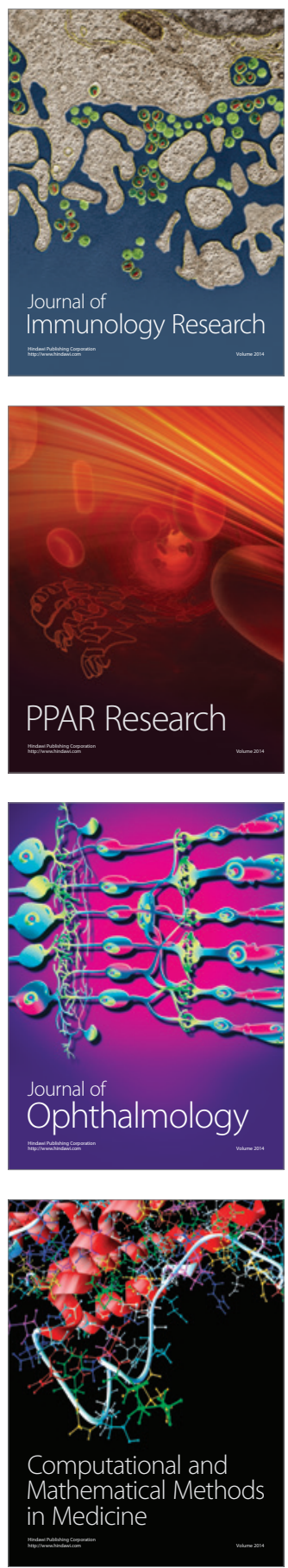

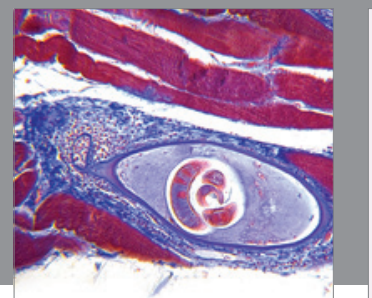

Gastroenterology

Research and Practice
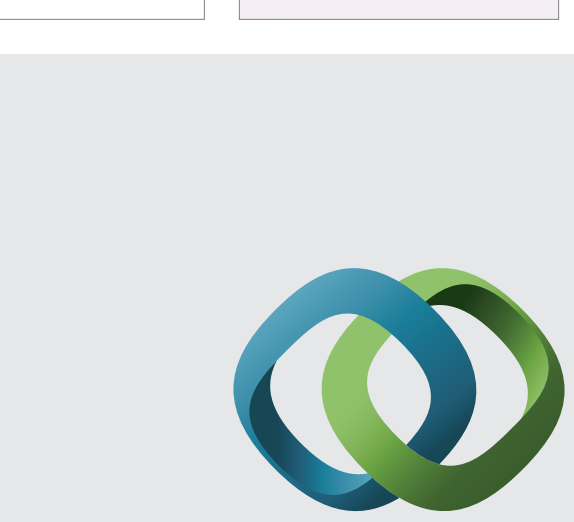

\section{Hindawi}

Submit your manuscripts at

http://www.hindawi.com
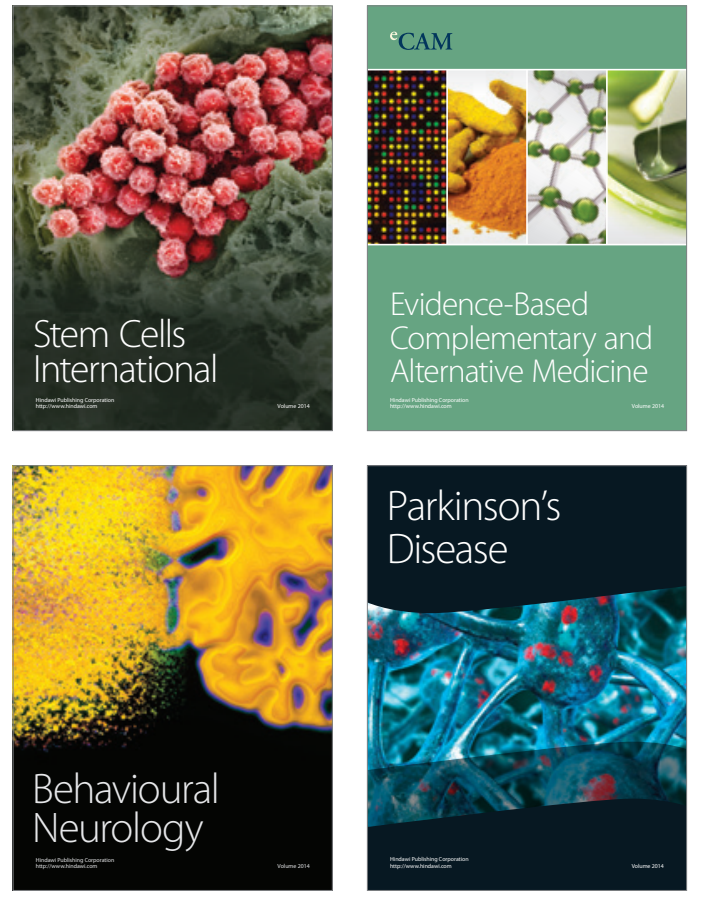
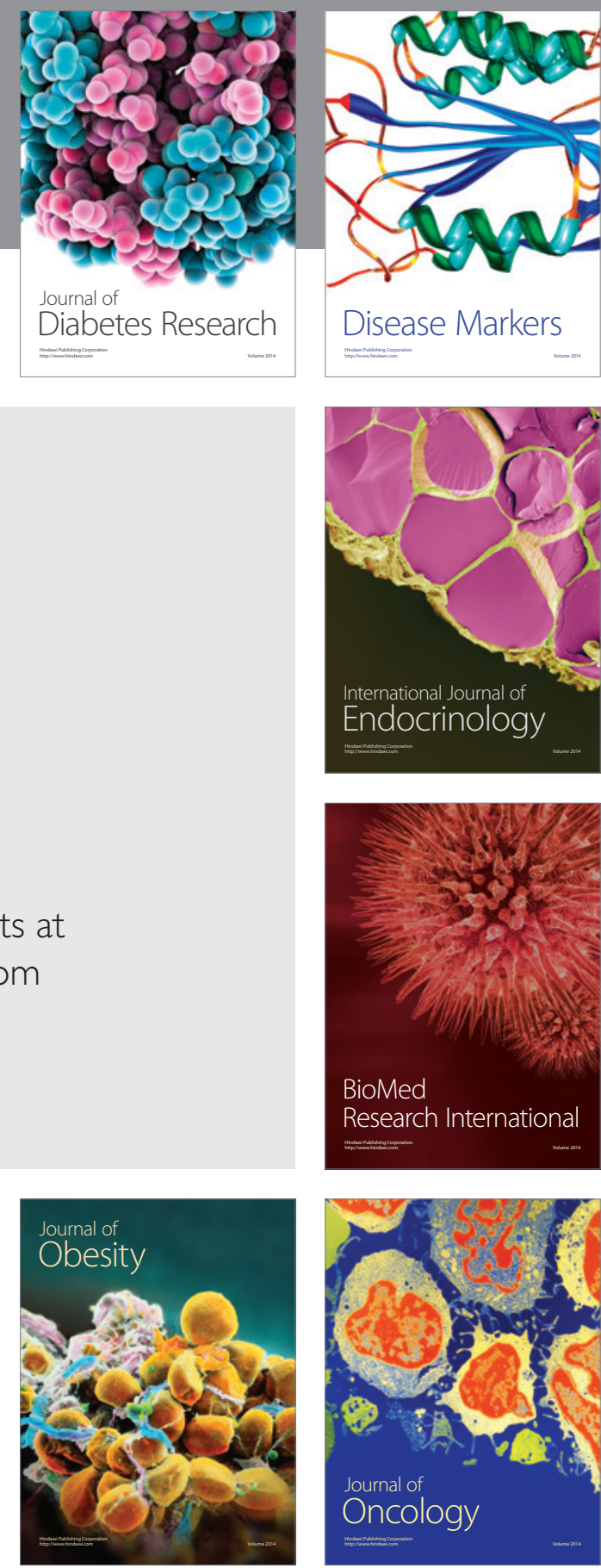

Disease Markers
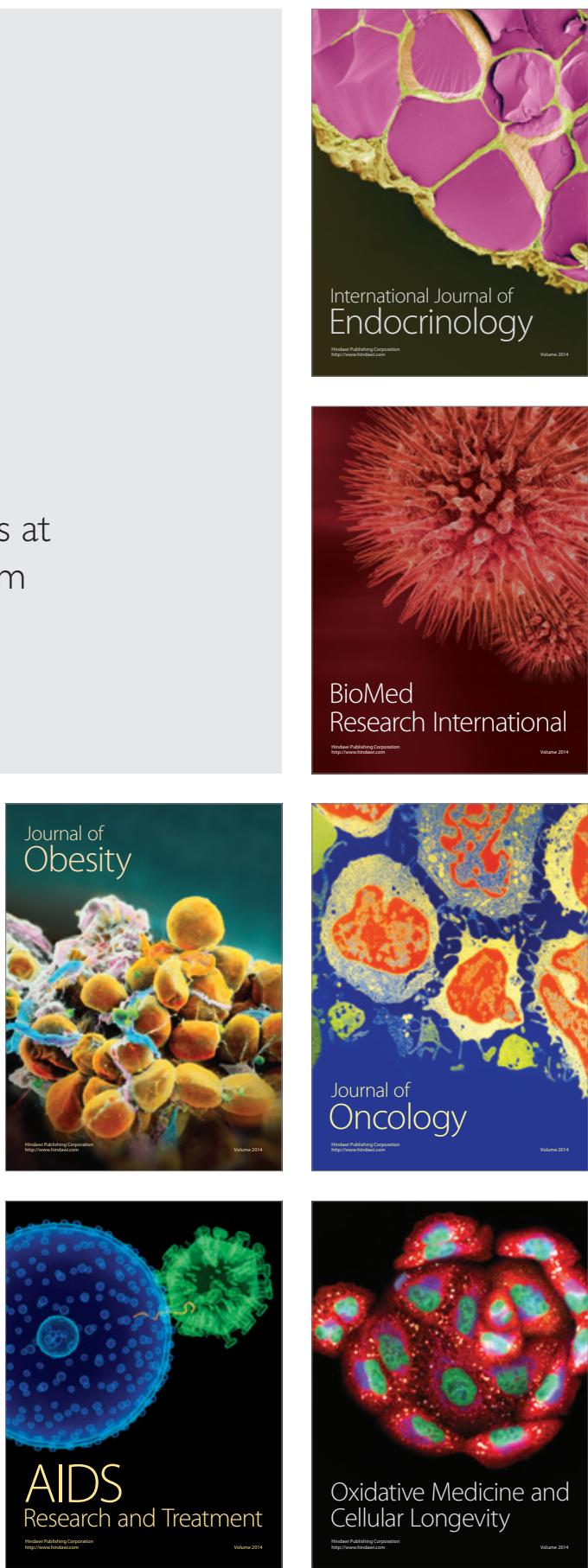